\title{
REVISTA CIENTÍFICA
}

Indicadores de Sustentabilidade Urbana: panorama das principais ferramentas utilizadas para gestão do desenvolvimento sustentável.

Urban Sustainability Indicators: overview of the main tools used to manage sustainable development.

Indicadores de Sustentabilidad Urbana: panorama de las principales herramientas utilizadas para la gestión del desarrollo sostenible.

Suise Carolina Carmelo de Almeida Aluna de Mestrado no PPGEU, UFSCar, Brasil eng.suise.cca@gmail.com

Luciana Márcia Gonçalves Professora Doutora, PPGEU, UFSCar, Brasil arq.luciana.ufscar@gmail.com 
RESUMO

Frente às mudanças que vêm ocorrendo no âmbito do planejamento urbano nas últimas décadas, decorrentes do crescimento global da consciência ecológica, faz se necessário observar as ações que os governos têm adotado para alcançar o objetivo de tornar as cidades mais sustentáveis e analisar sua eficácia. O Brasil insere-se nesse contexto através da adoção de algumas práticas alinhadas aos objetivos da Agenda 2030 como meta para os próximos anos. Este artigo, com base em pesquisa bibliográfica, traz um panorama dos principais programas e normas técnicas brasileiras que empregam metodologias de indicadores que abrangem a questão da sustentabilidade urbana, com foco na NBR ISO 37120:2017 - Desenvolvimento sustentável de comunidades - Indicadores para serviços urbanos e qualidade de vida, e que proporcionam contribuições significativas para a tomada de decisão. Esta norma, ainda pouco difundida no Brasil, trata- se de uma tradução idêntica da ISO 37120:2014, acrescida de algumas notas explicativas. $O$ presente artigo também analisa aspectos de sua aplicabilidade frente a realidade brasileira, visto a necessidade de superar algumas incompatibilidades de termos e metodologias para obtenção dos indicadores. Concluiu-se que apesar das contribuições geradas com a adoção dessas práticas, ainda há desafios a serem superados na construção de indicadores de sustentabilidade urbana de modo a agregar simultaneamente aspectos considerados imprescindíveis para promover mudanças na sociedade e subsidiar decisões de políticas públicas, questão complicada pela carência de infraestrutura de gestão urbana nos municípios, o que gera a necessidade de adaptações na obtenção dos indicadores devido à dificuldade de se produzir dados padronizados.

PALAVRAS-CHAVE: Indicadores. Sustentabilidade Urbana. NBR ISO 37120:2017.

\section{ABSTRACT}

This article focuses on the changes that have been taking place in the last decades in urban planning, based on a new ecological awareness from a global point of view. In this sense, there is a need to observe the actions that governments adopt to make their cities sustainable and how effective these actions are. Brazil as a country is included in this global context through: the adoption of practices aligned with the objectives of the 2030 Agenda, aiming at the implementation of these policies in the coming years. This work, based on a bibliographical research, brings a panorama of the main Brazilian technical standards and programs that use methodologies with indicators that address urban sustainability; This, based on NBR ISO 37120, 2017 - Sustainable community development - Indicators for urban services and quality of life, these indicators being indispensable tools for decision making. The norm under study, in fact, is not widespread in Brazil and it is a translation of ISO 37120, 2014 including some additional notes of the explanatory framework. The present investigation analyzes in turn aspects such as: the degree of applicability of these projects and standards to the Brazilian reality, since some incompatibilities arise in some terms and methodologies to obtain some indicators of decision making. Finally, it is concluded that, despite the contribution generated with these practices, there are challenges to be overcome in the construction of urban sustainability indicators, in order to simultaneously add aspects considered essential to promote changes in society and offer subsidies in the future. of public policy decisions, being a complex situation based on the lack of urban management infrastructure in the municipalities, which generates the need to adapt the way of obtaining the indicators in terms of the difficulty of obtaining standardized data.

KEY WORDS: Indicators. Urban Sustainability. NBR ISO 37120:2017.

\section{RESUMEN}

El presente artículo se enfoca en las mudanzas que vienen aconteciendo en las últimas décadas en lo tocante al planeamiento urbano, en función de una nueva conciencia ecológica desde un punto de vista mundial. En este sentido, surge la necesidad de observar las acciones que los gobiernos adoptan para tornar sus ciudades sustentables y que tan eficaces son estas acciones. Brasil como país se incluyen en este contexto mundial a través de: la adopción de prácticas alineadas a los objetivos de la Agenda 2030, visando la implementación de estas políticas en los próximos 


\section{REVISTA CIENTÍFICA $\quad 2018$}

años. Este trabajo, fundamentado en una investigación bibliográfica, trae un panorama de los principales programas y normas técnicas brasileñas que emplean metodologías con indicadores que abordan la sustentabilidad urbana; esto, fundamentado a través de la NBR ISO 37120;2017 - Desarrollo sustentable de comunidades - Indicadores para servicios urbanos y cualidad de vida, siendo estos indicadores herramientas indispensables para la toma de decisiones. La norma en estudio, de hecho, es poco difundida en Brasil y se trata de una traducción de la ISO 37120;2014 incluyendo algunas notas adicionales de marco explicativo. La presente investigación analiza a su vez aspectos como: el grado de aplicabilidad de estos proyectos y normas a la realidad brasileña, ya que surgen algunas incompatibilidades en algunos términos y metodologías para la obtención de algunos indicadores de toma de decisiones. Finalmente se concluye que, pese a la contribución generada con estas prácticas, existen desafíos a ser superados en la construcción de indicadores de sustentabilidad urbana, de modo a agregar de manera simultánea aspectos considerados imprescindibles para promover mudanzas en la sociedad y ofrecer subsidios en la toma de decisiones de políticas públicas, siendo una situación compleja en función de la falta de infraestructura de gestión urbana en los municipios, lo que genera la necesidad de adaptar la forma de obtener los indicadores en función de la dificultad de obtener datos estandarizados.

PALABRAS CLAVE: Indicadores. Sustentabilidad Urbana. NBR ISO 37120:2017. 


\section{REVISTA C I EN TÍF I C A 2018}

\section{INTRODUÇÃO}

A problemática do desenvolvimento sustentável tem ocupado lugar relevante no conjunto de reflexões das ciências, sobretudo a partir de meados do século $X X$, destacam-se também as discussões sobre a eficácia das instituições e das agências mundiais quanto ao planejamento do desenvolvimento urbano e da qualidade de vida da população. A forma na qual as construções e as cidades vêm sendo implantadas ao longo das décadas de avanço da urbanização gera danos, reversíveis ou não, ao meio ambiente. Frente a esta realidade, muito se discute atualmente sobre a questão da sustentabilidade ambiental. Portanto, a elaboração de métodos que avaliam a sustentabilidade de determinado local ou ação é de extrema importância para garantir a eficácia das medidas tomadas com o intuito de garantir ao ambiente construído uma tendência ambientalmente sustentável. (MASSIMINI e GONÇALVES, 2016)

Para Figueiredo (2017) o crescimento urbano desordenado é, hoje, um problema global e neste contexto, a avaliação de desempenho, por meio de ferramentas para a certificação de desenvolvimento urbano sustentável, surge como uma alternativa para orientar desenvolvedores imobiliários urbanos na tomada de decisão. Neste contexto, torna-se importante reverter o quadro de impactos ambientais negativos em que a maioria das cidades se encontra especialmente aquelas dos países subdesenvolvidos. Para tanto, é necessário que o modo com que as cidades são organizadas e gerenciadas seja aprimorado, de forma que haja um uso mais eficiente dos recursos.

Na busca de tornar as cidades cada vez mais sustentáveis, são editadas diferentes alternativas a partir da adoção de um modelo de desenvolvimento mais equilibrado, que considere conjuntamente as perspectivas econômicas, ambientais e sociais em oposição ao modelo focado estritamente na dimensão econômica. Para SARUBBI e MORAES (2017), essa tendência pode ser compreendida como uma resposta às pressões e acordos internacionais voltados ao desenvolvimento sustentável, aos planos e estratégias nacionais para sustentabilidade e às pressões da própria sociedade civil que começa a se conscientizar sobre a causa ambiental.

O crescimento da consciência ecológica pode ser acompanhado historicamente através das importantes reuniões globais que tiveram início em 1972, na Conferência das Nações Unidas sobre o Meio Ambiente (Conferência de Estocolmo), reunião organizada pela ONU onde chefes de estado se reuniram para tratar das questões relacionadas à degradação do meio ambiente. Em dezembro do mesmo ano foi criado o Programa das Nações Unidas para o Meio Ambiente (PNUMA), cujo encargo foi promover a liderança e encorajar parcerias no cuidado com o meio ambiente, inspirando, informando e capacitando nações e povos a aumentar sua qualidade de vida sem comprometer a das futuras gerações.

Anos depois, em 1987, após vários encontros da Comissão Mundial sobre o Meio Ambiente e Desenvolvimento, ficou consagrado o termo desenvolvimento sustentável na reunião conhecida como Comissão Brundtland, que produziu um relatório considerado básico para a definição desta noção e dos princípios que Ihe deram fundamento, no relatório "Nosso Futuro Comum", ou Relatório Brundtland, onde foi apresentado o conceito de desenvolvimento sustentável mais aceito até os dias de hoje, concebido como: $O$ desenvolvimento que satisfaz as necessidades 


\section{ANAP Brasil}

\section{REVISTA C I ENTÍFICA $\quad 2018$}

presentes, sem comprometer a capacidade das gerações futuras de suprir suas próprias necessidades.

Em 1992 na cidade do Rio de Janeiro/ Brasil foi escrito a Agenda 21, um conjunto de resoluções tomadas na conferência internacional Eco-92. Organizada pela ONU (Organização das Nações Unidas) contou com a participação de 179 países e resultou em medidas para conciliar crescimento econômico e social com a preservação do meio ambiente. Na Agenda 21 cada país definiu as bases para a preservação do meio ambiente em seu território, possibilitando o desenvolvimento sustentável.

Desde então, o conceito foi evoluindo e se adaptando, para AQUINO et al. (2014), a evolução do conceito de desenvolvimento sustentável, com foco no meio ambiente, para o de sustentabilidade, no qual são contemplados, além do meio ambiente, a sociedade e o capital, pode ser resumida na seguinte frase: um bom negócio deve ser ambientalmente correto, socialmente justo e economicamente viável. Assim, a gestão da sustentabilidade no âmbito dos países deve ser facilitada, estimulada e fomentada pelos seus governos, legitimados por formas democráticas de escolha.

Em 2015, 193 países se reuniram na ONU para negociações da Agenda 2030 que culminaram na adoção de 17 novos objetivos globais que servirão de roteiro para ajudar as nações a alcançarem o desenvolvimento sustentável, conhecido como os Objetivos de Desenvolvimento Sustentável (ODS). O objetivo número 11 trata especialmente sobre tornar as cidades e os assentamentos humanos inclusivos, seguros, resilientes e sustentáveis.

Hoje, mais da metade da população mundial vive em cidades e o mundo continua se urbanizando rapidamente. De acordo com as Nações Unidas, dois terços da população mundial viverão em áreas urbanas até 2050. No Brasil, o censo do Instituto Brasileiro de Geografia e Estatística (IBGE) de 2010 já apontava que 84,35\% da população vivem em áreas urbanizadas, ilustra-se então o panorama de quão grande é a importância desse objetivo frente ao contingente populacional que ele abrange. Sendo assim, faz-se necessário olhar o mundo de uma maneira diferente e planejar com cautela as ações que devem ser tomadas a fim de alcançar esses objetivos.

Em consonância com tais conceitos de sustentabilidade a Associação Brasileira de Normas Técnicas- ABNT traduziu para o português uma norma a ser aplicada às cidades brasileiras, indicadores que visam a medição do desempenho de gestão das cidades cujos principais objetivos: melhorar a qualidade de vida e promover a sustentabilidade. Nesse sentido LEITE (2012) destaca que qualquer transformação começa por um bom diagnóstico. No caso do sistema de indicadores de sustentabilidade urbana, significa uma importante mudança de patamar, outro olhar que permite, inclusive, melhor estruturar investimentos públicos. Os indicadores assim construídos e divulgados com transparência permitem mapear a evolução dos resultados e os impactos na qualidade da vida urbana da sociedade.

Apesar das diferentes metodologias já desenvolvidas e das tentativas de se trabalhar com parâmetros que objetivam alcançar padrões de Cidades Sustentáveis, pouco se tem de efetivo para cumprir esse objetivo. Ações dispersas dificultam a leitura de resultados, principalmente de forma comparativa. 


\section{REVISTA CIENTÍFICA $\quad 2018$}

Atualmente, existem diversas metodologias e programas que utilizam indicadores de sustentabilidade como ferramentas de mensuração e avaliação para a gestão ambiental urbana. Tais indicadores admitem diferentes formatos, alinhados a diferentes propostas de acordo com a realidade onde serão inseridos assim embasando resultados específicos, que variam de acordo com os objetivos de sua aplicação, como será demonstrado nesse artigo.

\section{OBJETIVOS}

Este artigo objetiva descrever quatro das principais ferramentas metodológicas de avalição de sustentabilidade. Tais ferramentas serão apresentadas através de seus indicadores e são considerados seus aspectos de apoio à gestão. Dentre os principais aspectos a serem considerados destacam-se: avaliação de gestão de sustentabilidade urbana e tomada de decisão nas políticas urbanas. São destacadas nas ferramentas selecionadas a importância cada vez maior do novo modo de planejar os espaços urbanos decorrente do movimento global em prol do desenvolvimento sustentável, caracteriza-se seus principais objetivos, e traça-se as considerações críticas sobre seus principais temas e resultados esperados.

\section{METODOLOGIA}

O desenvolvimento do trabalho baseou-se em pesquisa exploratória, consistindo na execução de amplo levantamento bibliográfico a partir da consulta de livros, artigos científicos, trabalhos acadêmicos e outros, para reunir o conhecimento já produzido acerca do tema geral do trabalho, metodologias de indicadores de sustentabilidade urbana, de modo a embasar o estudo teórico aqui descrito. As informações foram coletadas majoritariamente por meio de acesso aos sítios eletrônicos das entidades responsáveis pelas metodologias e outras fontes principais, com o intuito de coletar material para a elaboração dos pareceres que nos resultam mais recentes instrumentos de gestão urbana sustentável, incluindo a apresentação da análise das metodologias de indicadores de sustentabilidade selecionadas.

\section{RESULTADOS}

A seguir são relatados os principais instrumentos que objetivam definir metodologias de análise de gestão através de parâmetros, indicadores e outros sistemas que permitam alcançar os objetivos de desenvolvimento sustentável. Apesar de abrangente e por se tratar de tema muito interdisciplinar muitas metodologias convergem para os temas primordiais e princípios das dimensões básicas: social, econômica e ambiental. E busca-se através da dimensão institucional a viabilização das ações, políticas e programas relativos às demais dimensões. 


\section{ANAP Brasil}

\section{REVISTA CIENTÍFICA $\quad 2018$}

\subsection{Indicadores de Desenvolvimento Sustentável (IDS)}

Os Indicadores de Desenvolvimento Sustentáveis IDS, são baseados em recomendações da ONU, são formados de 63 indicadores, os quais buscam além de caracterizar e subsidiar o processo de desenvolvimento sustentável a nível nacional, também expressar as diversidades características do Brasil. Esses indicadores foram divididos em 4 dimensões: Ambiental, Social, Econômica e Institucional.

A dimensão ambiental contempla 19 indicadores que se relacionam aos objetivos de preservação e conservação do meio ambiente considerados fundamentais para a qualidade de vida, organizadas em 7 temas: Atmosfera, Terra, Água Doce, Oceanos, Mares e Áreas Costeiras, Biodiversidade e Saneamento.

A dimensão social é composta por 21 indicadores que correspondem especialmente aos objetivos ligados a satisfação das necessidades humanas, a melhoria da qualidade de vida, e a justiça social, abrangendo 6 temas: População, Educação, Trabalho e Rendimento, Habitação, Saúde e Segurança.

A dimensão econômica possui 11 indicadores que abordam 4 temas: Uso e esgotamento dos recursos, Produção e gerenciamento de resíduos, Uso de energia e Desempenho macroeconômico e financeiro. Por fim, a dimensão institucional apresenta 12 indicadores divididos em 2 temas: Orientação política e Capacidade e esforço na implementação das mudanças necessárias para que o desenvolvimento sustentável se torne realidade.

Os indicadores são uma importante ferramenta para auxiliar na obtenção do objetivo de alcançar o desenvolvimento sustentável, mostram-se mais úteis quando analisados em conjunto que individualmente, podendo fornecer um panorama mais completo fornecendo informações mais precisas acerca da condição global da sustentabilidade.

Eles servem de parâmetro para identificar se está ocorrendo um desenvolvimento e se o mesmo está se dando de maneira sustentável em todas as suas dimensões, de modo que se mantenha ao longo do tempo um equilíbrio estável entre padrões de consumo conscientes, que propicie a conservação dos recursos naturais e da diversidade ambiental além de promover uma sociedade mais igualitária, transparente e diversa culturalmente.

Segundo o IBGE, esses indicadores fornecem subsídios para o acompanhamento da sustentabilidade do padrão de desenvolvimento brasileiro nas dimensões ambiental, social, econômica e institucional, oferecendo um panorama abrangente de informações necessárias ao conhecimento da realidade do País, ao exercício da cidadania e ao planejamento e formulação de políticas públicas para o desenvolvimento sustentável.

Eles estão disponibilizados no Sistema IBGE de Recuperação Automática (SIDRA), um órgão que visa facilitar aos administradores públicos e à sociedade em geral, através da Internet, na obtenção gratuita dos dados agregados de estudos e pesquisas realizados pelo Instituto Brasileiro de Geografia e Estatística (IBGE). 


\section{ANAP Brasil}

\section{REVISTA CIENTÍFICA 2018}

\subsection{Programa Cidades Sustentáveis (PCS)}

Com o objetivo de colaborar no cumprimento da Agenda 2030 o Programa de Cidades Sustentáveis (PCS) incorporou os 17 objetivos do desenvolvimento sustentável e lançou uma carta-compromisso baseada em princípios apartidários e independentes que compromete os futuros prefeitos a elaborarem metas para o desenvolvimento sustentável com avaliação de resultados ao longo da gestão a partir dos 12 eixos do programa: Governança; Bens Naturais Comuns; Equidade, Justiça Social e Cultura de Paz; Gestão Local para a Sustentabilidade; Planejamento e Desenho Urbano; Cultura para a Sustentabilidade; Educação para a Sustentabilidade e Qualidade de Vida; Economia Local, Dinâmica, Criativa e Sustentável; Consumo Responsável e Opções de Estilo de Vida; Melhor Mobilidade, Menos Tráfego; Ação Local para a Saúde; Do Local para o Global.

O propósito é elaborar um diagnóstico dos municípios a partir dos indicadores do programa e criar metas para melhorar esses indicadores a partir das prioridades das cidades. Neste sentido, foram criados mais de 100 observatórios de indicadores a partir do software do PCS para melhor monitorar e planejar as políticas públicas em curto médio e longo prazo, trazendo transparência para a população. Para os signatários da carta-compromisso, foi desenvolvido um sistema para o preenchimento do relatório dos 260 indicadores básicos, disponível na plataforma do programa.

Em uma realização da Rede "Nossa São Paulo", da Rede Social Brasileira por Cidades Justas e Sustentáveis e do Instituto Ethos, o programa oferece uma plataforma que funciona como uma agenda para a sustentabilidade, incorporando de maneira integrada as dimensões social, ambiental, econômica, política e cultural e abordando as diferentes áreas da gestão pública em 12 eixos temáticos. A cada um deles estão associados indicadores, casos exemplares e referências nacionais e internacionais de excelência. Trata-se da tentativa de se criar oportunidade para o desenvolvimento de um novo padrão de relação dos cidadãos com a política, os candidatos assumindo compromissos concretos e os cidadãos acompanhando os resultados desses compromissos, alinhados com os Objetivos do Desenvolvimento Sustentável, da ONU.

\subsection{Programa Município Verde Azul (PMVA)}

Com o objetivo de medir e apoiar a eficiência da gestão ambiental nos municípios, descentralizar a política ambiental e promover as agendas ambientais locais, o Governo do Estado de São Paulo através da Secretaria Estadual do Meio Ambiente - SMA criou em 2007 o Programa Município Verde Azul - PMVA, visando o desenvolvimento e aplicação de Planos de Gestão Ambientais locais de curto, médio e longo prazos, por meio de uma agenda composta por 10 Diretivas que abordam questões prioritárias a serem desenvolvidas nos municípios.

Dessa forma seu principal objetivo é estimular e auxiliar o poder local das cidades pertencentes ao Estado de São Paulo na elaboração e execução de suas políticas públicas estratégicas para o desenvolvimento sustentável, incentivando e valorizando a presença da variável ambiental na 


\section{ANAP Brasil}

\section{REVISTA C IENTÍFICA $\quad 2018$}

agenda dos municípios. Com isso, o programa permite que seja realizada uma avaliação anual do desempenho das gestões ambientais dos municípios paulistas. A partir dessa avaliação, a SMA disponibiliza ao Governo do Estado de São Paulo, às prefeituras e à população o Indicador de Avaliação Ambiental - IAA.

O Programa vem mudando a gestão ambiental dos municípios do Estado de São Paulo como um todo a partir das ações locais nos 645 municípios do Estado. Os municípios devem se guiar pelas 73 ações englobadas dentro das 10 Diretivas do programa, colocando em prática sua agenda ambiental local através dessas ações. São elas: Esgoto Tratado (ET), Resíduos Sólidos (RS), Biodiversidade (BIO), Arborização Urbana (AU), Educação Ambiental (EA), Cidade Sustentável (CS), Gestão das Águas (GA), Qualidade do $\operatorname{Ar}(\mathrm{QA})$, Estrutura Ambiental (EM), e Conselho Ambiental (CA).

Posteriormente à pratica dessas ações, o município deve enviar à SMA um Relatório de Gestão Ambiental, juntamente com documentos comprobatórios das ações praticadas, assim feito, cada uma das ações recebe uma pontuação que vai de zero e cem, desse somatório descontamse os passivos ambientais do município, ou seja, os problemas ambientais do município por fim chegando a uma nota final, se a nota for igual ou superior a 80 o município recebe a certificação, ou selo, de Município VerdeAzul. A Secretaria Estadual do Meio Ambiente beneficia os 50 primeiros colocados do ranking de classificação do Programa com um incentivo financeiro repassado pelo FECOP - Fundo Estadual de Combate à Poluição, que financia os municípios na aquisição de equipamentos necessários para execução das ações. Os municípios que participam efetivamente do Programa, porém não conseguem atingir a nota mínima para receber a certificação também tem acesso à linha de financiamento da FECOP, os mesmos passam por uma avaliação para checar a necessidade de investimento para alavancar a prática das ações sustentáveis e conseguir atingir a pontuação necessária para receber a certificação. Os demais municípios, que não participam efetivamente perdem o direito a esse benefício no ano em questão como medida punitiva por não ter atingido a pontuação do programa.

\subsection{NRB ISO 37120:2017}

Com uma nova proposta para os próximos anos, a Associação Brasileira de Normas Técnicas (ABNT) publicou em janeiro de 2017 a primeira norma técnica nacional relacionada às cidades sustentáveis, a NBR ISO 37120:2017 - Desenvolvimento sustentável de comunidades Indicadores para serviços urbanos e qualidade de vida. Trata se de uma adoção idêntica, em conteúdo técnico, estrutura e redação, à ISO 37120:2014, que foi elaborada pelo Technical Committee Sustainable Development in Communities (ISO/TC 268), o trabalho de estudo e tradução da norma internacional já existente para esse tema foi feito pela Comissão de Estudos Especial 268 da ABNT, coordenada pelo professor Eng. Abiko do Departamento de Engenharia de Construção Civil (PCC) da Escola Politécnica da Universidade de São Paulo (Poli-USP), que afirma que não bastava apenas traduzir para a Língua Portuguesa, mas fazer uma avaliação técnico-científica do documento, pois não se pode simplesmente alterar uma norma ISO para adotá-la ou para que ela passe a ser uma norma NBR ISO, é preciso fazer adaptações em itens 


\section{ANAP Brasil}

\section{REVISTA CIENTÍFICA $\quad 2018$}

para que a norma faça sentido ou seja adaptada à realidade brasileira, o que foi feito por meio de notas.

No histórico de realização desta tradução e adaptação ao caso brasileiro o trabalho envolveu diversas instituições e órgãos públicos, tais como a Caixa, Ministério das Cidades, Sabesp, Conselho de Arquitetura e Urbanismo (CAU), Câmara Brasileira da Indústria da Construção (CBIC), Sindicato da Habitação (Secovi), Conselho Brasileiro da Construção Sustentável (CBCS), Poli-USP, Faculdade de Arquitetura e Urbanismo da USP (FAU-USP),Companhia de Desenvolvimento do Estado de São Paulo (CDHU), Instituto de Engenharia, entre outras, que compuseram a CEE 268, Comissão de Estudos Especial de Desenvolvimento Sustentável em Comunidades espelho do ISO/TC 268, Sustainable development in communities.

A NBR ISSO 37120:2017 tem como princípio geral a sustentabilidade e segundo sua própria apresentação foi concebida para auxiliar as cidades a direcionar e avaliar a gestão de serviços urbanos e toda a prestação de serviços, assim como a qualidade de vida da população, ela é aplicável a qualquer cidade, municipalidade ou governo local que pretenda medir seu desempenho de uma forma comparável e verificável, independentemente do tamanho e da localização.

A sua elaboração envolveu diversos técnicos e instituições interessados no assunto e busca suprir a necessidade identificada pela sociedade brasileira de dispor de um documento normativo que norteasse o controle e monitoramento do progresso de desempenho das cidades em atingir o desenvolvimento sustentável.

Os indicadores associados pela Norma Técnica são estruturados em torno de temas, e dividemse em três tipos: indicadores essenciais, indicadores de apoio e indicadores de perfil. Os indicadores essenciais são considerados indispensáveis para direcionar e avaliar o desempenho da gestão dos serviços urbanos e a qualidade de vida, portanto são essenciais na implementação dessa norma. Os indicadores de apoio têm função complementar, a fim de se obter melhores práticas é conveniente que também sejam aplicados. Já os indicadores de perfil têm a função de servir como uma referência, pois fornecem estatísticas básicas e informações do contexto para auxiliar na identificação de quais cidades são interessantes para comparações aos pares. Os indicadores essenciais e de apoio estão divididos em 17 categorias, são elas: Economia, Educação, Energia, Meio Ambiente, Finanças, Resposta a Incêndios e Emergências, Governança, Saúde, Recreação, Segurança, Habitação, Resíduos Sólidos, Telecomunicações e Inovação, Transporte, Planejamento Urbano, Esgotos, Água e Saneamento. Para a interpretação de dados, a norma sugere que as cidades devem levar em consideração a análise do contexto vivido no momento da interpretação de resultados, pois o ambiente institucional local pode afetar a capacidade de aplicação de indicadores.

\subsection{Visão crítica dos Instrumentos}

O número de programas de cunho ambiental que abrangem as cidades brasileiras é um bom exemplo da incorporação de boas práticas sustentáveis, estas e outras ações contribuem para evidenciar a importância da conservação e preservação do meio ambiente por meio da injeção 


\section{ANAP Brasil}

\section{REVISTA C I ENTÍFICA $\quad 2018$}

de capital em um número crescente de projetos sustentáveis. Neste aspecto é importante salientar a abrangência de cada um dos programas a fim de que se possam observar quais os aspectos mais relevantes que estão sendo levados em consideração na construção dessas ferramentas. No Quadro 1 estão descritas as estruturas de indicadores utilizadas pelas metodologias pesquisadas, e a sua abrangência.

Quadro 1: Organização dos indicadores das metodologias pesquisadas

\begin{tabular}{|c|c|c|c|}
\hline Metodologia & Abrangência & Organização dos Indicadores & No de Indicadores \\
\hline $\begin{array}{c}\text { Indicadores do Desenvolvimento } \\
\text { Sustentável - IDS }\end{array}$ & Nacional & 4 Dimensões de Sustentabilidade & 63 \\
\hline Programa Cidades Sustentáveis - PCS & Nacional & 12 Eixos Temáticos & 260 \\
\hline $\begin{array}{c}\text { Programa Município Verde Azul - } \\
\text { PMVA }\end{array}$ & $\begin{array}{c}\text { Regional } \\
\text { (São Paulo) }\end{array}$ & 10 Diretivas Ambientais & 10 \\
\hline NBR ISO 37120:2017 & Internacional & 17 Seções de Indicadores & 100 \\
\hline
\end{tabular}

Fonte : AUTOR, 2018

Em geral, apesar de tratarem dos mesmos aspectos, os instrumentos não apresentam redundância, sendo que a utilização de um deles não exclui a utilização de outro, uma vez que as abordagens são diferentes, mesmo que todos usem a metodologia de indicadores. A princípio a adoção de uma ou mais dessas ferramentas é um aspecto positivo para alcançar o objetivo de tornar as cidades mais sustentáveis já que isoladamente nenhuma delas abrange todas os aspectos que devem ser considerados.

Num país tão vasto como o Brasil, a existência de uma única ferramenta que compreendesse de forma sintetizada toda as particularidades de informações de cada região e de cada município seria algo bastante complexo que demoraria um longo tempo para ser incorporada por todos os municípios, testada, adaptada e constatada sua real eficência como ferramenta de auxílio à gestão do desenvolvimento sustentável. Nesse ponto, o apoio institucional de universidades e centros de pesquisa seria de grande importância para o desenvolvimento dessa ferramenta unificada de mensuração do desempenho das cidades em alcançar o desenvolvimento sustentável.

Como um vislumbre dessa ferramenta pode-se considerar o trabalho do Instituto Brasileiro de Geografia e Estatística (IBGE), instituição consolidada responsável pela coleta de dados e produção de informações de caráter multitemático das dimensões da realidade nacional, trazendo importantes indicadores do território brasileiro.

É uma importante fonte de dados para as ferramentas aqui mencionadas, porém o tempo entre os sensos e a divulgação dos dados dificulta a sua utilização pela carência de fornecer dados atualizados anualmente, o que é de suma importância para um controle real do progresso alcançado, daí percebe-se a importância de tornar o processo de coleta e análise simplificado e rápido. Essa crítica também se aplica ao SIDRA - Sistema IBGE de Recuperação Automática que disponibiliza os Indicadores do Desenvolvimento Sustentável.

O Programa Cidades Sustentáveis, conta com uma plataforma online bem estruturada que pode ser consultada abertamente, porém não se encontram a maioria dos dados, percebe-se uma grande falta da colaboração por parte dos municípios para alimentação das informações. 


\section{REVISTA CIENTÍFICA 2018}

Atualmente o PCS conta com a adesão de 22 estados, e um total de 193 cidades, dentre elas apenas 11 capitais. Mostra-se necessário uma maior participação para gerar resultados, ainda mais agora que o Brasil se comprometeu em estar em conformidade com os novos parâmetros de desenvolvimento da ONU, uma vez que os eixos do Programa Cidades Sustentáveis dialogam diretamente com os Objetivos do Desenvolvimento Sustentável.

O Programa Município VerdeAzul conta, desde 2008, com a adesão de $100 \%$ dos municípios paulistas, se mostrando em termos comparativos, o mais bem-sucedido nesse quesito. Porém, o número de munícipios que participam efetivamente do ranking tem caído nos últimos anos como mostrado no Gráfico 1. O que pode indicar uma possível queda no esforço dos municípios com relação às questões relacionadas ao desenvolvimento sustentável ou a possível dificuldade de se manter no ranking tendo em vista os crescentes e não cumulativos critérios de avaliação e pontuação das atividades, obras, programas ou posturas.

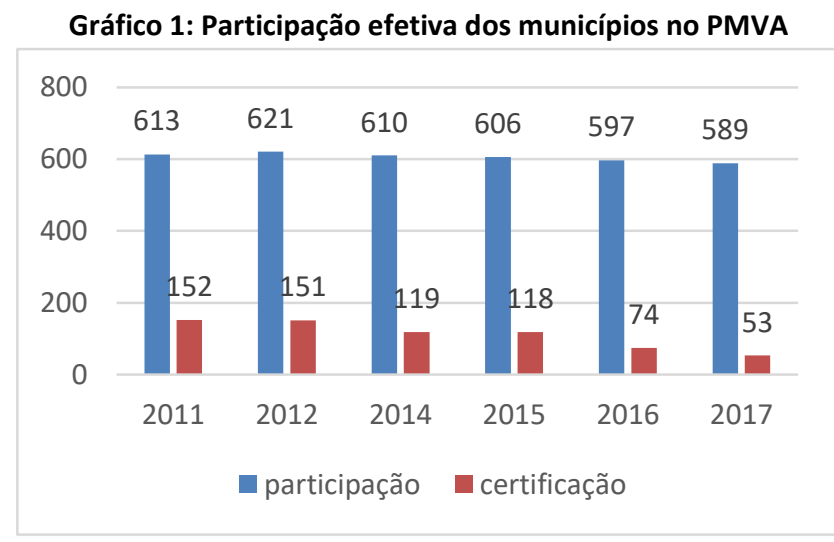

Fonte : AUTOR, 2018

Observação: naõ existem dados de 2013 no site http://verdeazuldigital.sp.gov.br/site/pontuacoes/. 


\section{REVISTA CIENTÍFICA $\quad 2018$}

Do ponto de vista da NBR ISO 37120:2017, pode-se afirmar que algumas normas não atravessam fronteiras com total eficácia logo de cara, não pela sua qualidade, mas devido os ajustes necessários a serem feitos para adequação ao novo contexto em que está sendo inserida, pois podem surgir problemas quando não há informações suficientes para sua correta aplicação. Observa-se que nessa norma foram criados indicadores mais especificos porém ainda não completamente detalhados do ponto de vista da obtenção dos dados que podem promover o uso desses indicadores. Essa norma pode ser mais uma dessas difíceis transformações, uma vez que se caracteriza por uma tradução com alguns ajustes em expressões segundo a realidade Brasileira, que por si só, ja necessita de parâmetros muito diferentes devido sua extensão territorial, diferenças culturais, fisicas e geográficas. Uma das maiores dificuldades existentes para a aplicabilidade destas normas definidas pela ISO é que os governos locais, cidades ou municípios não produzem dados de maneira padronizada. Seja para um mesmo Estado ou entre municípios de mesmo porte, a diferenciação na coleta, organização e disponibilização das informações torna muito difícil a padronização e principalmente a comparação entre cidades. Ainda não se tem informações consolidadas para análise da aplicabilidade da Norma e tão pouco quanto à sua eficácia devido ao fato de ser ainda uma norma muito recente (2014 e no Brasil 2017), porém já há estudos relacionados sendo realizados. Este artigo é parte da pesquisa de mestrado no programa de pós graduação em Engenharia Urbana da Universidade Federal de São Carlos, no qual será analisada a NBR ISO 37120:2017 aplicada a dois municipios de porte médio do interior do estado de São Paulo.

\section{CONCLUSÃO}

Confirma-se a relevância dos indicadores destacados pelas ferramentas do estudo como subsídio de tomada de decisão para a gestão pública urbana. Foram destacados aspectos considerados nos indicadores que auxiliam as instituições que definem políticas públicas urbanas, e no desenvolvimento e implementação dessas ferramentas e instrumentos. Parâmetros extraídos a partir de análises empíricas de intervenções públicas se prestam também a uma adaptação em distintos contextos e proporcionam avaliação da aplicabilidade e eficácia das ações adotadas. Em geral, a implementação bem-sucedida de políticas se associa a ferramentas criadas ou adaptadas especialmente para tratar de problemas locais diagnosticados pelas autoridades, mas mais importante que a qualidade de uma ferramenta, o sucesso ou $o$ fracasso depende de muitos fatores, entre os quais destacam-se o próprio processo de produção, coleta e armazenamento de dados assim como sua aplicação. Evidencia-se também que quanto mais detalhado e bem definido o indicador, mais o mesmo pode colaborar com o desenvolvimento de políticas públicas e no processo de ranking ou comparação para fins de avaliação de empenho e análise de resultados.

A avaliação destacou que cada metodologia possui potencialidades e aborda aspectos específicos, e diferenças fundamentais em relação à abrangência, objetivo e especialmente considerando-se as dimensões da sustentabilidade abordadas. Assim, levanta-se a hipótese de 


\section{ANAP $\mathscr{B}_{\text {rasil }}$}

\section{REVISTA CIENTÍFICA 2018}

que não existe uma metodologia de indicadores de sustentabilidade ideal, mas sim aquela melhor adaptada a um determinado contexto.

Conclui-se que, mais do que ferramentas de avaliação do desempenho ambiental, as metodologias de indicadores influenciam positivamente os municípios no desenvolvimento de boas práticas sustentáveis. As inúmeras tentativas de organizar indicadores para gestão ambiental urbana podem confluir para a NBR ISO 37120, uma vez que aborda grande amplitude de aspectos.

Nota-se que a NBR ISO 37120 apresenta uma abordagem abrangente, possibilita comparação entre municípios independente do porte dos mesmos e pode colaborar para análise da situação da sustentabilidade local, principalmente em municípios com poucos indicadores. Porém desde uma análise preliminar encontra-se a dificuldade de encontrar dados formatados em parâmetros a serem aproveitados na aplicação dos indicadores contidos nessa norma.

A dificuldade de encontrar tais dados coletados pelos institutos e organismos oficiais concorre para que outras metodologias sejam mais facilmente aceitas e gerem mais resultados imediatos apesar de pouco abrangentes.

Uma das principais sugestões que essa pesquisa propõe a partir da análise dos métodos é a necessidade de padronização na coleta de organização dos dados municipais seja em sua forma ou na elaboração dos parâmetros qualitativos e quantitativos uma vez que os municípios brasileiros ainda não possuem, nem produzem grande parte dos indicadores nela presente. Além disso, faz-se necessária a comunicação entre as diferentes secretarias municipais e outros órgãos responsáveis pela produção desses dados, para que seja feita de forma integrada e colaborativa, uma vez que os indicadores geram informações importantes quando analisados em conjunto. Feito isso esses dados devem ser divulgados em formato aberto para dar maior visibilidade dessas informações proporcionando um aprofundamento na democracia e na conscientização da população, uma vez que a experiência que pode ser observada pode trazer grandes benefícios locais pelo compartilhamento de melhores práticas, além do fato de que as administrações municipais representam o nível de governo mais próximo dos cidadãos brasileiros, tendo a oportunidade única de influenciar comportamentos sociais e individuais no sentido da sustentabilidade.

\section{REFERÊNCIAS BIBLIOGRÁFICAS}

ABNT. Associação Brasileira de Normas Técnicas. NBR ISO 37120:2017: Desenvolvimento sustentável de comunidades - Indicadores para serviços urbanos e qualidade de vida. Rio de Janeiro. 2017.

AQUINO, A. R. et al. Indicadores de desenvolvimento sustentável: uma visão acadêmica. 1. ed. Rio de Janeiro: Rede Sirius, 2014.

BELLEN, H. M. V. Indicadores de sustentabilidade: uma análise comparativa. 2. ed. Rio de Janeiro: Editora FGV, 2006. $256 \mathrm{p}$.

FERNADES, A. C. et al. Desenvolvimento, planejamento e governança: expressões do debate contemporâneo. 1. ed. Rio de Janeiro: Letra Capital: ANPUR, 2015. 502 p. Editora UFPE. 


\section{REVISTA CIENTÍFICA 2018}

FIGUEIREDO, P. P. R. A. et al. Avaliação de desempenho para o desenvolvimento do urbanismo sustentável: Revisão de literatura e diretrizes para futuras investigações. Mix Sustentável. Florianópolis, 2017. v.3. n.2. p.114-124.

GUIA GPS - $\quad$ Gestão $\quad$ Pública $\quad$ Sustentável. Disponível em: <http://www.cidadessustentaveis.org.br/arquivos/gest\%C3\%A3o-p\%C3\%BAblicasustent\%C3\%A1vel.pdf>. Acesso em: 06 de março de 2018.

LEITE, C; AWAD, J. C. M. Cidades sustentáveis, cidades inteligentes: desenvolvimento sustentável num planeta urbano. Porto Alegre: Bookman, 2012. 264 p.

MASSIMINI, B., GONÇALVES, L. M. Análise de Sustentabilidade Urbana: estudo de caso do campus da Universidade Federal de São Carlos. Pluris 2016 - Maceió- Alagoas.

MUNICIPIO VERDEAZUL. O Programa. Disponível em: <http://verdeazuldigital.sp.gov.br/site/oprojeto/>. Acesso em: 11 abril. 2018.

MUNICÍPIO VERDEAZUL. Ranking. Disponível em: <http://verdeazuldigital.sp.gov.br/site/pontuacoes/>. Acesso em: 31 maio 2018.

PROGRAMA CIDADES SUSTENTÁVEIS. Indicadores. Disponível em: < http://indicadores.cidadessustentaveis.org.br/\#state91>. Acesso em: 31 maio de 2018.

RIBEIRO; R. GONÇALVES; L. Cidades jardins e sustentabilidade: o significado do verde. CONGRESSO NOVOS DIREITOSCidades em crise? São Carlos. 2015. UFSCar.

SARUBBI, M. P.; MORAES, C.S.B. Avaliação comparativa de metodologias de indicadores para a sustentabilidade urbana. IGCE- UNESP. São Carlos. 2017. SINGEURB.

SIDRA. Indicadores de Desenvolvimento Sustentável - IDS. Disponível em: <https://sidra.ibge.gov.br/pesquisa/ids/tabelas>. Acesso em: 12 abril 2018.

SIMÕES, J. Docente da Poli-USP coordena grupo que elabora normas técnicas para cidades sustentáveis. Disponível em: <http://www.poli.usp.br/pt/comunicacao/noticias/2275docente-da-poli-usp-coordena-grupo-que-elaboranormas-tecnicas-para-cidadessustentaveis.html>. Acadêmica Agência de Comunicações. Acesso em: Sex, 31 de março de 2017. 